\title{
Prevalence of primary anti-tuberculosis drug resistance at the tertiary center in Saudi Arabia and associated risk factors
}

Mohammed S. Al-Shahrani, BSc, MSc, Majed I. Hakami, MD, Mahmoud A. Younis, MD, PhD, Hanan A. Fan, MD, Mohammed A. Jeraiby, MD, Yasser Alraey, MSc, PhD.

\section{ABSTRACT}

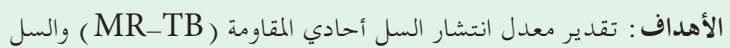

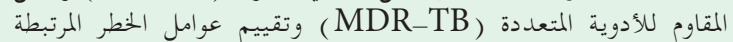

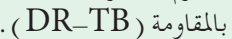

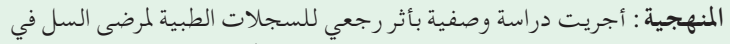

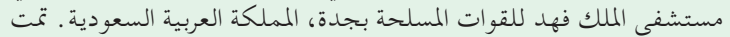

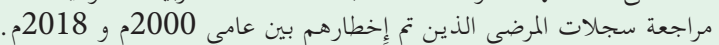

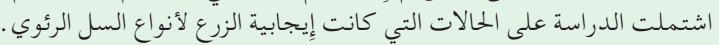

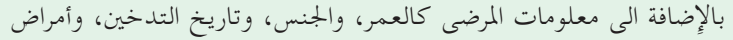

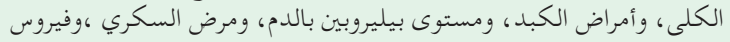

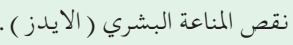

النتائج : تم إِشراك 901 حالة في الدراسة، من بينها ( 191.40 لم 193 حالة

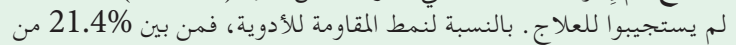

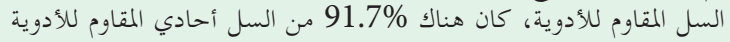

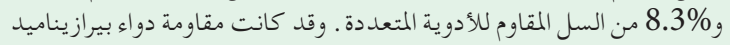

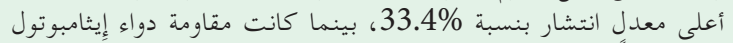

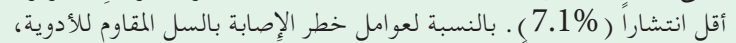

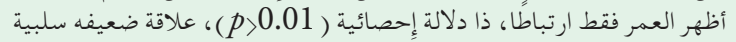
(r=-0.145)

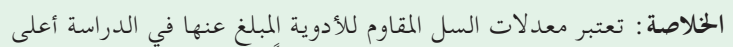

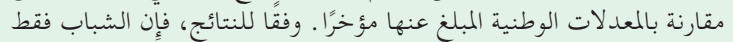

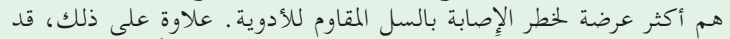

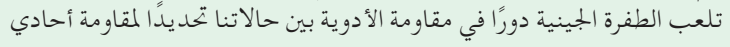

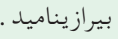

Objectives: To estimate the prevalence mono-resistant tuberculosis (MR-TB) and multidrug resistant TB (MDR-TB), and evaluate the risk factors associated with the drug-resistant tuberculosis (DR-TB).

Methods: A descriptive, retrospective study was applied, utilizing the TB patients' medical records at King Fahd Armed Forces Hospital (KFAFH), Jeddah, Saudi Arabia. The records of patients notified between 2000 and 2018 were reviewed and culture positive cases for Mycobacterium tuberculosis species were included. Moreover, the risk factors included were age, gender, smoking history, renal disease, liver disease, hyperbilirubinemia, diabetes mellitus, and human immunodeficiency virus (HIV).

Results: Nine hundred and one cases in entirety were involved in the research, out of which $193 \mathrm{had}$ drug-resistant tuberculosis (DR-TB) (21.4\%). Out of the $21.4 \%$ DR-TB, $91.7 \%$ were MR-TB and $8.3 \%$ were MDR-TB. The highest MR prevalence was for pyrazinamide at $33.4 \%$, while the lowest resistance was for ethambutol at $7.1 \%$. For the risk factors of drug-resistant $\mathrm{TB}$, only age depicted a statistically significant $(p<0.01)$ but weak negative $(r=-0.145)$ correlation with anti-TB drug resistance.

Conclusion: Rates of DR-TB reported in the study are considered higher compared to the recently reported national and international rates. According to the results, only younger people are at risk of developing DR-TB. Moreover, genetic mutation may play a role in drug resistance among our cases specifically for pyrazinamide monoresistance.

Keywords: prevalence, primary, anti-tuberculosis, drug, resistant, risk factors.

Saudi Med J 2021; Vol. 42 (7): 728-734 doi: 10.15537/smj.2021.42.7.20200797

From the Department of Medical Laboratory (Al-Shahrani), Department of Pulmonary Medicine (Younis, Fan), King Fahd Armed Forces Hospital, Jeddah; Saudi Ministry of Health (Hakami), King Fahd Central Hospital; from the Biochemistry Department (Jeraiby), Faculty of Medicine, Jazan University, Jazan; and from Department of Clinical Laboratory Sciences (Alraey), College of Applied Medical Sciences, King Khalid University, Abha, Kingdom of Saudi Arabia.

Received 1st January 2021. Accepted 4th May 2021.

Address correspondence and reprint request to: Dr. Yasser Alraey, Department of Clinical Laboratory Sciences, College of Applied Medical Sciences, King Khalid University, Abha, Kingdom of Saudi Arabia.E-mail:yahamd@kku.edu.sa

ORCID ID: https://orcid.org/0000-0002-5809-7525 
$\mathrm{T}$ uberculosis (TB) is an infectious disease primarily caused by the Mycobacterium tuberculosis species that spread through aerosols. Globally, it is the ninth main cause of mortality, and the foremost cause of mortality resulting from a single contagious affliction, even exceeding HIV. ${ }^{1,2}$ In spite of the accomplishment of prevention and control strategies, it is one of the foremost causes of mortality in Saudi Arabia. ${ }^{3,4}$ Recently, it has been ranked 11th among causes of death in Saudi Arabia, with approximately 65,000 cases reported in the Kingdom between 1991 and $2010 .^{5}$ One of the main contributors to TB-related deaths is drug resistance. In 2013, the World Health Organization (WHO) announced that multidrugresistant TB (MDR-TB), distinct as Mycobacterium tuberculosis, is resistant to both isoniazid and rifampicin, 2 of the most formidable anti-TB drugs. ${ }^{6}$ In addition, the world is witnessing the emergence of a wide range drug-resistant strains of TB (XDR-TB), which are categorized as resistant to both isoniazid and rifampicin, in addition to one fluroquinolone drug, and one of the second-line injectable drugs (kanamycin, amikacin, and capreomycin)., ${ }^{7,8}$ The treatment of MDR-TB requires a long course of expensive and toxic drugs. ${ }^{9}$ Moreover, despite being an enormous financial load, drug-resistant TB is associated with poor outcomes, having a mortality rate close to $90 \%$ if accompanied by HIV. ${ }^{10-13}$ According to the literature, the treatment of drug resistant TB (DR-TB) has a considerably lower success rate, reaching 52\% for MDR-TB and $28 \%$ for XDR-TB, compared to $82 \%$ for drug-susceptible TB. ${ }^{14}$ The reported causes for drug-resistant strains in Mycobacterium tuberculosis are poor adherence to TB medications, inappropriate utilization of anti-TB drugs, spontaneous chromosomal mutations, and treatment failure. ${ }^{15-17}$ In addition, experts have suggested that inadequate healthcare systems, insufficient political commitment, unsound drug policies, poor disease management, and long-standing neglect in research have facilitated the global rise of DR-TB. ${ }^{18,19}$ In Saudi Arabia, the MDR-TB rates are reported to be between $1 \%$ and $5 \% .{ }^{20} \mathrm{~A}$ national study published in 2013 by Al-Hajoj et $\mathrm{al}^{21}$ reported a total MDR-TB rate of $4 \%$. In a recent local study, $\mathrm{Al}$ Ammari et al found that the rate of MDR-TB is $4.4 \%$, while the rates of mono-resistance (MR) are $3.8 \%$ for ethambutol, $5.4 \%$ for pyrazinamide,

Disclosure. Authors have no conflict of interests, and the work was not supported or funded by any drug company.
$10.2 \%$ for isoniazid, $11 \%$ for streptomycin, and $5.9 \%$ for rifampicin. This study found that women, younger age groups and those with a history of TB had a higher rate of MDR. ${ }^{14}$ Multidrug-resistant TB has become a significant issue worldwide due to its community-based and cost-effective consequences. ${ }^{22}$ Jeddah, being a tourist and business hub, has the potential to escalate communicable infections. Close contact between people for a long duration elevates the danger of the escalation of respiratory infections.

Our study aims to assess the rates of MR and MDR in Jeddah in Saudi Arabia. We were also deeply interested in the interrelation between the demographic status, clinical attributes, and the grades of resistance in the studied population.

Methods. This cross-sectional study was conducted by retrospectively collecting data from the medical records of TB patients between 2000 and 2018 in King Fahd Armed Forces Hospital (KFAFH), a tertiary hospital and JCI accredited organization with a capacity of 540 beds in Jeddah, Saudi Arabia. Ethical approval was obtained from the Ethical and Research Committee (REC-248) at KFAFH, Jeddah, Saudi Arabia.

A total of 901 patients were included in this study as they showed a positive culture for mycobacteria $\mathrm{TB}$ and completed the regimen of anti-tuberculosis medication. Those who did not complete the regimen of anti-tuberculosis medication were excluded from this study. Furthermore, the exclusion criteria were applied to patients who showed positive culture of mycobacteria TB.

For mycobacteria diagnosis, clinical samples are screened by performing an acid-fast bacilli smear and culturing in the Bactec MGIT 960 liquid system (Becton, Dickinson, New Jersey, USA), which contains $7 \mathrm{~mL}$ of modified Middlebrook $7 \mathrm{H} 9$ broth base. The MGITTM OADC enrichment and PANTA antibiotic mixture (Becton, Dickinson, New Jersey, United states), are also used for mycobacteria cultivation. ${ }^{23}$ With the exception of blood and urine samples, all types of clinical samples can be used for primary isolation in the MGIT tube. The sputum sample was the most common type of sample received during this period for Mycobacterium tuberculosis diagnosis, as shown in Figure 1.

This study defined drug resistance as resistance to at least one of the following: isoniazid, rifampicin, pyrazinamide, ethambutol, and streptomycin. MDR-TB was defined as being resistant to at least isoniazid and rifampicin. The variables used include age, gender, smoking history, renal disease, liver disease, hyperbilirubinemia, diabetes mellitus, and HIV. All 
age groups were included. Serum creatinine was taken as a marker of impaired renal function. According to the national kidney foundation, a creatinine level greater than $1.4 \mathrm{mg} / \mathrm{dL}$ for men and $1.2 \mathrm{mg} / \mathrm{dL}$ for women was an early sign of renal disease. If the level of serum creatinine was higher than the above level, then creatinine clearance was estimated by glomerular filtration rate. $^{24}$ Serum aminotransferases, alanine aminotransferase (ALT), aspartate aminotransferase (AST), and total bilirubin were taken as biochemical markers for liver injury. The sensitivity and specificity of serum aminotransferases, particularly serum ALT, for differentiating liver disease from non-liver disease depended on the cut-off values chosen to define an abnormal test. The cut off value for serum ALT for men is 33 units/L and women 25 units/L. In children, the cut off value for ALT for boys is 38 and girls 32 units/L. ${ }^{25}$ The serum AST cut off value for men is 40 and women 32 units/L. Total bilirubin was used to assess hyperbilirubinemia with a cut off value of $1.0 \mathrm{mg} / \mathrm{dl}$.

Statistical analysis was performed using the Statistical Package for Social Sciences software, version 24.0 (Armonk, NY: IBM Corp.). All factors affecting the treatment responses were included in our analyses (namely, age, gender, nationality, smoking history, renal failure, liver failure, hyperbilirubinemia, diabetes mellitus, and HIV). Multivariate logistical regression analyses were applied to predict the possible risk factors and Spearman correlation analysis was used to validate the statistical significance of the different factors. Variables with $p<0.05$ in the multivariate analysis were considered to be statistically significant.
Results. There were 901 participants. More than half of them $(55.8 \%)$ were males and the remainder were female $(44.2 \%)$. The vast majority $(96.1 \%)$ were Saudi, and the largest proportion (29.3\%) was in the age group of $21-40$ years followed by $27.1 \%$ in the age group of 61-80 years. The data is presented in Table 1 .

Overall, more than three quarters $(78.6 \%)$ of the patients were sensitive to anti-tuberculosis drugs, which was noted to decrease throughout the follow-up period: being $90.5 \%$ from 2000 to 2002 and peaking at $79.6 \%$ in the years from 2012-2014. Furthermore, $21.4 \%$ of cases were resistant to anti-TB drugs, and the resistance rate increased during the follow-up period from 9.5\% to $33.7 \%$ in the periods of 2000-2002 and 2009-2011, respectively, as shown in Table 2.

It was found that out of the $21.4 \%$ resistant patients, 91.7\% were mono-resistant $\mathrm{TB}$ and $8.3 \%$ were multi drug-resistant TB. The results reveal that during the follow-up years, the prevalence of mono-resistant TB decrease ranged from $85.7 \%$ to $100 \%$ from 2000 to 2014, and in the last follow-up period (2015-2018), it became $67.7 \%$. In contrast, MDR-TB was highly prevalent in the last year (2015-2018) reaching 32.3\% even though its rate dramatically decreased or was even absent (zero) after the first follow up years in which it was $14.3 \%$. The data is shown in Table 2.

Table 3 shows the prevalence of resistance to each of the primary anti-tuberculosis drugs. The highest resistance prevalence was for pyrazinamide at 33.4\%, followed by isoniazid at $26.7 \%$, and streptomycin at $20.6 \%$, while the lowest reported resistance was for ethambutol at $7.1 \%$. Regarding the multivariate logistical regression analyses, none of the possible risk

Table 1 - Comparison of tuberculosis patients according to various parameters.

\begin{tabular}{|c|c|c|c|c|c|c|c|}
\hline Parameters & $2000-2002$ & $2003-2005$ & $2006-2008$ & $2009-2011$ & $2012-2014$ & $2015-2018$ & $\begin{array}{c}\text { Total } \\
\text { n (\%) }\end{array}$ \\
\hline \multicolumn{8}{|l|}{ Age (years) } \\
\hline $0-20$ & 0 & 5 & 16 & 14 & 11 & 15 & $61(6.8)$ \\
\hline $21-40$ & 28 & 42 & 55 & 58 & 37 & 44 & $264(29.3)$ \\
\hline $41-60$ & 41 & 50 & 45 & 39 & 18 & 22 & $215(23.9)$ \\
\hline $61-80$ & 42 & 62 & 57 & 42 & 21 & 20 & $244(27.1)$ \\
\hline$>80$ & 37 & 30 & 21 & 13 & 6 & 10 & $117(13.0)$ \\
\hline Total & 148 & 189 & 194 & 166 & 93 & 111 & $901(100)$ \\
\hline \multicolumn{8}{|l|}{ Gender } \\
\hline Female & 61 & 92 & 96 & 81 & 29 & 39 & 398 (44.2) \\
\hline Male & 87 & 97 & 98 & 85 & 64 & 72 & $503(55.8)$ \\
\hline Total & 148 & 189 & 194 & 166 & 93 & 111 & $901(100)$ \\
\hline \multicolumn{8}{|l|}{ Nationality } \\
\hline Non-Saudi & 7 & 5 & 8 & 7 & 3 & 5 & $35(3.9)$ \\
\hline Saudi & 141 & 184 & 186 & 159 & 90 & 106 & $866(96.1)$ \\
\hline Total & 148 & 189 & 194 & 166 & 93 & 111 & $901(100)$ \\
\hline
\end{tabular}


Table 2 - Drugs sensitive/resistant tuberculosis with resistant pattern.

\begin{tabular}{|c|c|c|c|c|c|c|c|}
\hline $\begin{array}{l}\text { Drugs sensitive/ } \\
\text { resistant }\end{array}$ & $2000-2002$ & $2003-2005$ & $2006-2008$ & $2009-2011$ & $2012-2014$ & $2015-2018$ & $\begin{array}{l}\text { Total } \\
\text { n }(\%)\end{array}$ \\
\hline \multicolumn{8}{|l|}{ Drug susceptibility } \\
\hline Sensitive & $134(90.5)$ & $162(85.7)$ & $148(76.3)$ & $110(66.3)$ & 74 (79.6) & $80(72.1)$ & $708(78.6)$ \\
\hline Resistant & $14(9.5)$ & $27(14.3)$ & $46(23.7)$ & $56(33.7)$ & $19(20.4)$ & $31(27.9)$ & $193(21.4)$ \\
\hline Total & 148 & 189 & 194 & 166 & 93 & 111 & $901(100)$ \\
\hline \multicolumn{8}{|l|}{ Resistant pattern } \\
\hline Mono-resistant & $12(85.7)$ & $27(100)$ & $43(93.5)$ & $55(98.2)$ & $19(100)$ & $21(67.7)$ & $177(91.7)$ \\
\hline Multi-resistant & $2(14.3)$ & 0 & $3(6.5)$ & $1(1.8)$ & 0 & $10(32.3)$ & $16(8.3)$ \\
\hline Total & 14 & 27 & 46 & 56 & 19 & 31 & $193(100)$ \\
\hline
\end{tabular}

Table 3 - Prevalence of primary mono-drug resistant tuberculosis

\begin{tabular}{lccccccc}
\hline Mono-drug resistant & $\mathbf{2 0 0 0 - 2 0 0 2}$ & $\mathbf{2 0 0 3 - 2 0 0 5}$ & $\mathbf{2 0 0 6 - 2 0 0 8}$ & $\mathbf{2 0 0 9 - 2 0 1 1}$ & $\mathbf{2 0 1 2 - 2 0 1 4}$ & $\mathbf{2 0 1 5 - 2 0 1 8}$ & $\begin{array}{c}\text { Total } \\
\mathbf{n}(\%)\end{array}$ \\
\hline Ethambutol & 5 & 3 & 3 & 3 & 1 & 6 & $\mathbf{2 1}(7.1)$ \\
Isoniazid & 6 & 3 & 21 & 25 & 8 & 16 & $\mathbf{7 9}(\mathbf{2 6 . 7})$ \\
Pyrazinamide & 0 & 4 & 27 & 32 & 16 & 20 & $\mathbf{9 9}(33.4)$ \\
Rifampicin & 3 & 15 & 4 & 3 & 0 & 11 & $\mathbf{3 6}(\mathbf{1 2 . 2})$ \\
Streptomycin & 4 & 5 & 18 & 18 & 0 & 16 & $\mathbf{6 1}(\mathbf{2 0 . 6})$ \\
Total & 18 & 30 & 73 & 81 & 25 & 69 & $\mathbf{2 9 6}(\mathbf{1 0 0})$ \\
\hline
\end{tabular}

factors have shown a statistically significant association, except for HIV patients. Statistically, it appears that MTB drug resistance is more strongly correlated with non-HIV patients. However, in this study, we only found one positive case of HIV. Importantly, Saudi Arabia remains a low HIV prevalence country with approximately $1.5 / 100,000$ cases yearly. ${ }^{26}$ The data is shown in Table 4.

The Pearson correlation coefficient was calculated to assess the risk factors for drug resistance (overall resistance), and the results are shown in Table 5. For the correlation of tested factors with patients who showed both mono-resistance and multi-resistance to TB treatment, there was a statistically significant $p$-value $(p<0.01)$ weak negative $(r=-0.145)$ association between age and anti-TB drug resistance. For the other assessed factors (gender, CREAT, ALT, AST, TBIL, and diabetes $)$, the association is weakly negative $(r=-0.001$, $r=-0.024, r=-0.025, r=-0.062, r=-0.009$, and $r=-0.011$, respectively), but statistically non-significant since all $p>0.05$. However, smoking showed a weakly positive borderline-significant association with drug resistance $(\mathrm{r}=0.054, p=0.053)$. For the individual Spearman's correlation of multi-resistance and mono-resistance, it was found that all the assessed factors showed a weak association, either positive or negative, with nonsignificant statistical correlation $(p>0.05)$.
Discussion. This study found that the rate of MDR-TB is significantly high at $8.3 \%$, which is almost double that of the $\mathrm{Al} \mathrm{Ammari} \mathrm{study.}{ }^{14}$ The prevalence of any drug-resistant $\mathrm{TB}$ in our study was $21.4 \%$, which is higher than the recently published German study $(12.7 \%)^{2}$ but is much lower than Iranian study (41.6\%). ${ }^{27}$ Monoresistance accounted for more than $90 \%$ of any DR-TB, which is parallel to the results of Glasauer's study. ${ }^{2}$

This study observed that the rate of DR-TB increased over time. This is opposite to Oman's study, ${ }^{28}$ which revealed that the rate of drug-resistant $\mathrm{TB}$ decreased in follow up time. The rate of mono-resistant TB peaked in 2009 while MDR-TB peaked in 2016. This issue could be explained by expansion in rapid molecular testing and the availability of the GeneXpert system which was implemented in our hospital in 2007. A study conducted in Saudi Arabia over a period of 15 years showed that isoniazid has the highest mono-resistance followed by ethambutol, while in our study ethambutol has the lowest rate of monoresistance; however, the resistant rate for ethambutol is approximately the same at $7.5 \%$ and $7.1 \%$ respectively. ${ }^{29}$

According to the WHO's 2016 report, the global rate of MDR-TB is $4.1 \%$ and it caused approximately 240,000 deaths. According to our data, the MDR-TB rate has doubled and is now $8.3 \% .^{30} \mathrm{~A}$ systemic review carried out in Europe in 2006 showed that previous 
Table 4 - Possible risk factors associated with mono-drug, multi-drug resistant tuberculosis.

\begin{tabular}{|c|c|c|c|c|c|}
\hline Variables & Mono-resistant & Multi-resistant & Odds ratio & $\begin{array}{c}95 \% \\
\text { confidence } \\
\text { interval }\end{array}$ & $P$-value \\
\hline \multicolumn{6}{|l|}{ Smoking } \\
\hline Yes & 26 & 3 & 1.305 & $0.39-4.3$ & \multirow{2}{*}{0.663} \\
\hline No & 151 & 13 & 0.95 & $0.85-1.11$ & \\
\hline \multicolumn{6}{|l|}{ Gender } \\
\hline Female & 77 & 8 & 1.5 & $0.69-1.93$ & \multirow{2}{*}{0.616} \\
\hline Male & 100 & 8 & 0.89 & $0.53-1.47$ & \\
\hline \multicolumn{6}{|l|}{ Nationality } \\
\hline Saudi & 164 & 16 & 1.1 & $1.05-1.15$ & \multirow{2}{*}{0.262} \\
\hline Non-Saudi & 13 & 0 & & & \\
\hline \multicolumn{6}{|l|}{ Creatinine } \\
\hline Normal & 83 & 3 & 0.96 & 0.93-1.01 & \multirow{2}{*}{0.421} \\
\hline High & 18 & 0 & & & \\
\hline \multicolumn{6}{|c|}{ Alanine aminotransferase } \\
\hline Normal & 124 & 5 & \multirow{2}{*}{0.96} & \multirow{2}{*}{ 0.93-0.99 } & \\
\hline High & 26 & 0 & & & \\
\hline \multicolumn{6}{|l|}{$A S T$} \\
\hline Normal & 51 & 1 & 0.98 & 0.94-1.02 & \multirow{2}{*}{0.643} \\
\hline High & 11 & 0 & & & \\
\hline \multicolumn{6}{|l|}{ Total bilirubin } \\
\hline Normal & 111 & 3 & 0.4 & $0.13-1.25$ & \multirow{2}{*}{0.157} \\
\hline High & 21 & 2 & 1.4 & $0.7-.9$ & \\
\hline \multicolumn{6}{|c|}{ Diabetes mellitus } \\
\hline Normal & 91 & 3 & 0.65 & $0.21-1.99$ & \multirow{2}{*}{0.488} \\
\hline High & 32 & 2 & 1.23 & $0.6-2.5$ & \\
\hline \multicolumn{6}{|l|}{$H I V$} \\
\hline Negative & 177 & 15 & 12.8 & $7.87-20.8$ & \multirow{2}{*}{0.001} \\
\hline Positive & 0 & 1 & 0.078 & $0.05-0.13$ & \\
\hline
\end{tabular}

Table 5 - Correlation of tested factors with patients showed resistance to TB treatment either (multi and/or mono) compared to non-resistant patients.

\begin{tabular}{|c|c|c|c|c|c|c|c|c|c|}
\hline Variables & Age & Gender & Creatinine & ALT & AST & $\begin{array}{c}\text { Total } \\
\text { bilirubin }\end{array}$ & $\begin{array}{c}\text { Diabetes } \\
\text { mellitus }\end{array}$ & SMOK & HIV \\
\hline \multicolumn{10}{|l|}{$\begin{array}{l}\text { Spearman's rho resistance } \\
\text { (mono \& multi) }\end{array}$} \\
\hline Correlation coefficient & $-0.145^{* *}$ & -0.001 & -0.024 & -0.025 & -0.062 & -0.009 & -0.011 & 0.054 & 0.064 \\
\hline Sig. (2-tailed) & 0.000 & 0.483 & 0.272 & 0.241 & 0.117 & 0.398 & 0.383 & 0.053 & 0.055 \\
\hline $\mathrm{N}$ & 901 & 901 & 647 & 805 & 370 & 752 & 713 & 901 & 901 \\
\hline \multicolumn{10}{|c|}{ Correlation of tested factors with patients showed multi-resistance to TB treatment compared to mono-resistant patients. } \\
\hline \multicolumn{10}{|c|}{$\begin{array}{l}\text { Spearman's rho multi- } \\
\text { resistance }\end{array}$} \\
\hline Correlation coefficient & 0.020 & 0.036 & -0.079 & -0.082 & -0.058 & 0.121 & 0.061 & -0.031 & $0.24^{* *}$ \\
\hline Sig. (2-tailed) & 0.780 & 0.618 & 0.426 & 0.311 & 0.649 & 0.159 & 0.492 & 0.665 & 0.001 \\
\hline $\mathrm{N}$ & 193 & 193 & 104 & 155 & 63 & 137 & 128 & 193 & 193 \\
\hline \multicolumn{10}{|c|}{ Correlation of tested factors with patients showed Mono-resistance to TB treatment compared to Multi-resistant patients. } \\
\hline \multicolumn{10}{|l|}{$\begin{array}{l}\text { Spearman's rho mono- } \\
\text { resistance }\end{array}$} \\
\hline Correlation coefficient & -0.020 & -0.036 & 0.079 & 0.082 & 0.058 & -0.121 & -0.061 & 0.031 & $-0.24^{* *}$ \\
\hline Sig. (2-tailed) & 0.780 & 0.618 & 0.426 & 0.311 & 0.649 & 0.159 & 0.492 & 0.665 & 0.001 \\
\hline $\mathrm{N}$ & 193 & 193 & 104 & 155 & 63 & 137 & 128 & 193 & 193 \\
\hline
\end{tabular}


treatment with anti-TB drugs is the strongest factor for developing MDR-TB. ${ }^{18,31}$ In addition, improper dose or the presence of a low concentration of anti-TB drugs in the serum may facilitate drug resistance and delay the eradication of the TB pathogen. ${ }^{32}$

Among the risk factors included, there was a significant association between the younger age group and resistance to anti-TB drugs, this association was observed in other previous published studies.,15 A recently published Chinese study showed that males have a higher rate of drug resistance than females, which supports our findings regarding mono-resistant cases (odd ratio [OR] 0.89; 95\% CI 0.53-1.47). ${ }^{33}$ Gender has no significant risk of MDR-TB in our study. However, Gaifer et $\mathrm{al}^{28}$ reported that females have a statistical association with DR-TB. Regarding other possible risk factors, our results showed a positive association between smoking and DR-TB. However, this association is weak and a borderline significant. This finding is within the same context as the previous systemic review ${ }^{34}$ and meta-analysis study. ${ }^{35}$ There is a lack of research on the association between renal and liver failure with DR-TB. In this study, we did not find a significant correlation between renal or liver failure with the rate of DR-TB. A recently published systemic review and meta-analysis showed that diabetes mellitus has no significant impact on rifampicin monoresistant or MDR-TB. ${ }^{36}$ This result is compatible with our findings that there is a weak and non-statistically significant association between diabetes mellitus and DR/MDR TB.

The previous literature states that HIV patients infected with TB have an increased mortality rate. ${ }^{12,13,37}$ Moreover, a cross sectional study showed that HIV does not appear to be a risk factor for MDR-TB. ${ }^{36}$ Saudi Arabia is a low HIV prevalence country, and it has a low HIV/TB co-infection rate. ${ }^{26}$ Only one case of MDR-TB experienced HIV co-infection. Consequently, it is difficult to evaluate the association between HIV and DR-TB.

Study limitations. Though we provided sufficient evidence to support our conclusions, it is a single-center study that only includes patients of Arab ethnicity. Due to the nature of the study, namely, retrospective, we were unable to analyze the modifiable factors such as patient compliance, which may have a role in developing anti-TB resistant. Besides, additional information of other MDR-TB patients was not accessible and genetic mutation study, which may lead to a high rate of MDR-TB.

There are certain points that make our study different from the existing literature. First, we used a large sample compared to other studies. Second, TB drug-resistance increased during the follow-up period. In addition, there is no association between DR-TB and gender. However, further studies are needed to identify the mechanism of drug resistance in TB patients.

In conclusion, pyrazinamide has the highest resistance prevalence. In addition, no risk factors appear to have a strong significant association with DR-TB, either MR or MDR. Accordingly, we believe that there are underlying genetic mutations, which could cause patients infected with TB to develop drug resistance. A recently published study that supports our hypothesis shows that among 318 clinical isolates smear-positive $\mathrm{TB}$, the prevalence of the pncA mutation in isolates resistant to first-line anti-TB drugs was significantly higher than drug-susceptible isolates. ${ }^{38}$ Even with the limitations present in this study, our results determined the overall MR and MDR-TB rate over the follow-up period and the factors associated with such resistance in Saudi Arabia which might help policymakers to address the rising concern of DR-TB in Saudi Arabia.

Acknowledgment. We are indebted to our colleagues at King Fahd Armed Forces Hospital, Jeddah, Saudi Arabia in all aspects related to data collection. We also would like to thank Dr. Mohammad M. Alam for valuable statistical advice.

\section{References}

1. World Health Organization. Global tuberculosis report 2019. World Health Organization; 2020. Available from: https://apps.who.int/iris/bitstream/ handle/10665/329368/9789241565714-eng.pdf

2. Glasauer S, Altmann D, Hauer B, Brodhun B, Haas W, Perumal N. First-line tuberculosis drug resistance patterns and associated risk factors in Germany, 2008-2017. PLoS One 2019; 14: e0217597.

3. Aljadani R, Ahmed AE, Al-Jahdali H. Tuberculosis mortality and associated factors at King Abdulaziz Medical City Hospital. BMC Infect Dis 2019; 19: 427.

4. Abouzeid MS, Al Hakeem RF, Memish ZA. Mortality among tuberculosis patients in Saudi Arabia (2001-2010). Ann Saudi Med 2013; 33: 247-252.

5. Al-Orainey I, Alhedaithy MA, Alanazi AR, Barry MA, Almajid FM. Tuberculosis incidence trends in Saudi Arabia over 20 years: 1991-2010. Ann Thorac Med 2013; 8: 148-152.

6. Stosic M, Vukovic D, Babic D, Antonijevic G, Foley KL, Vujcic I, et al. Risk factors for multidrug-resistant tuberculosis among tuberculosis patients in Serbia: A case-control study. BMC Public Health 2018; 18: 1114.

7. Dheda K, Gumbo T, Maartens G, Dooley KE, McNerney R, Murray M, et al. The epidemiology, pathogenesis, transmission, diagnosis, and management of multidrug-resistant, extensively drug-resistant, and incurable tuberculosis. Lancet Respir Med 2017: S2213-2600(17)30079-6.

8. Vasava MS, Bhoi MN, Rathwa SK, Borad MA, Nair SG, Patel HD. Drug development against tuberculosis: Past, present and future. Indian J Tuberc 2017; 64: 252-275. 
9. Caminero JA, García-Basteiro AL, Rendon A, Piubello A, Pontali E, Migliori GB. The future of drug-resistant tuberculosis treatment: Learning from the past and the 2019 World Health Organization consolidated guidelines. Eur Respir J 2019; 54: 1901272.

10. Marks SM, Hirsch-Moverman Y, Salcedo K, Graviss EA, Oh P, Seaworth B, et al. Characteristics and costs of multidrugresistant tuberculosis inpatient care in the United States, 2005-2007. Int J Tuberc Lung Dis 2016; 20: 435-441.

11. Zhang P, Xu G, Song Y, Tan J, Chen T, Deng G. Challenges faced by multidrug-resistant tuberculosis patients in three financially affluent Chinese cities. Risk Manag Healthc Policy 2020; 13: 2387-2394.

12. Fiebig L, Kollan C, Hauer B, Gunsenheimer-Bartmeyer B, an der Heiden M, Hamouda $\mathrm{O}$, et al. HIV-Prevalence in Tuberculosis Patients in Germany, 2002-2009: An Estimation Based on HIV and Tuberculosis Surveillance Data. PLoS One 2012; 7: e49111.

13. Naidoo K, Naicker N. Epidemiology of drug-susceptible, drugresistant tuberculosis and HIV in Africa. In: Sereti I, Bisson GP, Meintjes G, editors. HIV and Tuberculosis. Switzerland (AG): Springer Nature; 2020.

14. Al Ammari M, Al Turaiki A, Al Essa M, Kashkary AM, Eltigani SA, Ahmed AE. Drug resistant tuberculosis in Saudi Arabia: An analysis of surveillance data 2014-2015. Antimicrob Resist Infect Control 2018; 7: 12.

15. Kane JC, Elafros MA, Murray SM, Mitchell EMH, Augustinavicius JL, Causevic S, et al. Focus on drug-resistant tuberculosis. Antimicrob Resist Infect Control 2018; 7: 12.

16. Pettit AC, Cummins J, Kaltenbach LA, Sterling TR, Warkentin $\mathrm{J} \mathrm{V}$. Non-adherence and drug-related interruptions are risk factors for delays in completion of treatment for tuberculosis. Int J Tuberc Lung Dis 2013; 17: 486-492.

17. Abdella K, Abdissa K, Kebede W, Abebe G. Drug resistance patterns of Mycobacterium tuberculosis complex and associated factors among retreatment cases around Jimma, Southwest Ethiopia. BMC Public Health 2015; 15: 599.

18. European Centre for Disease Prevention and Control. Tuberculosis surveillance and monitoring in Europe 2017. Sweden (SW): European Centre for Disease Prevention and Control.

19. Van Der Werf MJ, Ködmön C, Hollo V, Sandgren A, Zucs P. Drug resistance among tuberculosis cases in the European Union and European economic area, 2007 to 2012. Eurosurveillance 2014; 19: pii=20733.

20. Chaudhry LA, Rambhala N, Al-Shammri AS, Al-Tawfiq JA. Patterns of antituberculous drug resistance in Eastern Saudi Arabia: A 7-year surveillance study from 1/2003 to 6/2010. J Epidemiol Glob Health 2012; 2: 57-60.

21. Al-Hajoj S, Varghese B, Shoukri MM, Al-Omari R, Al-Herbwai M, AlRabiah F, et al. Epidemiology of antituberculosis drug resistance in Saudi Arabia: Findings of the first national survey. Antimicrob Agents Chemother 2013; 57: 2161-2166.

22. Sambas MFMK, Rabbani U, Al-Gethamy MMM, Surbaya SH, Alharbi FFI, Ahmad RGA, et al. Prevalence and determinants of multidrug-resistant tuberculosis in Makkah, Saudi Arabia. Infect Drug Resist 2020; 13: 4031-4038.

23. Lewinsohn DM, Leonard MK, Lobue PA, Cohn DL, Daley CL, Desmond E, et al. Official American Thoracic Society/ Infectious Diseases Society of America/Centers for Disease Control and Prevention Clinical Practice Guidelines: Diagnosis of Tuberculosis in Adults and Children. Clin Infect Dis 2017; 64: 111-115.
24. KDIGO. 2012 Clinical Practice Guideline for the Evaluation and Management of Chronic Kidney Disease. Nephrol Dial 2017; 7: 1-59.

25. Kwo PY, Cohen SM, Lim JK. ACG Clinical Guideline: Evaluation of Abnormal Liver Chemistries. Am J Gastroenterol 2017; 112: 18-35.

26. Al Mazroa MA, Kabbash IA, Felemban SM, Stephens GM, Al-Hakeem RF, Zumla AI, et al. HIV Case Notification Rates in the Kingdom of Saudi Arabia over the Past Decade (20002009). PLoS One 2012; 7: e45919.

27. Shamaei M, Marjani M, Chitsaz E, Kazempour M, Esmaeili M, Farnia P, et al. First-line anti-tuberculosis drug resistance patterns and trends at the national TB referral center in Iran-eight years of surveillance. Int J Infect Dis 2009; 13: e236-e240.

28. Gaifer Z, Babiker A, Rizavi D. Epidemiology of drug-resistant tuberculosis in a tertiary care center in Oman, 2006-2015. Oman Med J 2017; 32: 36-40.

29. Al-Tawfiq JA, Al-Muraikhy AA, Abed MS. Susceptibility pattern and epidemiology of Mycobacterium tuberculosis in a Saudi Arabian Hospital: A 15-year study from 1989 to 2003. Chest 2005; 128: 3229-3232.

30. Falzon D, Linh Nhat N, Ernesto J, Karin W. The global response to rifampicin-resistant tuberculosis: Current situation and recent trends. European Respiratory Journal 2016; 48: PA1903.

31. Tanoue LT. Risk factors for multidrug resistant tuberculosis in Europe: a systematic review. Yearbook of Pulmonary Disease 2007; 2007: 353-354.

32. Xu Y, Wu J, Liao S, Sun Z. Treating tuberculosis with high doses of anti-TB drugs: Mechanisms and outcomes. Ann Clin Microbiol Antimicrob 2017; 16: 67.

33. Wu X, Yang J, Tan G, Liu H, Liu Y, Guo Y, et al. Drug resistance characteristics of mycobacterium tuberculosis isolates from patients with tuberculosis to 12 antituberculous drugs in China. Front Cell Infect Microbiol 2019; 9: 345.

34. Ullah I, Javaid A, Tahir Z, Ullah O, Shah AA, Hasan F, et al. Pattern of drug resistance and risk factors associated with development of drug resistant mycobacterium tuberculosis in Pakistan. PLoS One 2016; 11: e0147529.

35. Wang MG, Huang WW, Wang Y, Zhang YX, Zhang MM, Wu SQ, et al. Association between tobacco smoking and drugresistant tuberculosis. Infection and Drug Resistance 2018; 11 : 873-887.

36. Baya B, Achenbach CJ, Kone B, Toloba Y, Dabitao DK, Diarra $\mathrm{B}$, et al. Clinical risk factors associated with multidrug-resistant tuberculosis (MDR-TB) in Mali. Int J Infect Dis 2019; 81: 149-155.

37. Chingonzoh R, Manesen MR, Madlavu MJ, Sopiseka N, Nokwe M, Emwerem M, et al. Risk factors for mortality among adults registered on the routine drug resistant tuberculosis reporting database in the Eastern Cape Province, South Africa, 2011 to 2013. PLoS One 2018; 13: e0202469.

38. Cao Z, Lan Y, Chen L, Xiang M, Peng Z, Zhang J, et al. Resistance to first-line antituberculosis drugs and prevalence of pnca mutations in clinical isolates of mycobacterium tuberculosis from zunyi, guizhou province of China. Infect Drug Resist 2019; 12: 3093-3102. 